\title{
Optimasi Polivinil Pirolidon dan Kitosan dalam Sediaan Mucoadhesive Buccal Film Diltiazem HCl
}

\section{(Optimization Of Polyvinyl Pyrrolidone and Chitosan in Mucoadhesive Buccal Film Diltiazem HCl)}

\author{
Viddy Agustian Rosyidi, Ulfia Dwi Novita, Lusia Oktora Ruma Kumala Sari \\ Fakultas Farmasi Universitas Jember \\ Jln. Kalimantan 37, Jember 68121 \\ e-mail: viddy.farmasi@unej.ac.id
}

\begin{abstract}
Diltiazem $\mathrm{HCl}$ is a class of benzoatiazepine calcium channel blocker used in treatment of angina pectoris, arrhythmias, and hypertension. Diltiazem $\mathrm{HCl}$ improves first pass metabolism, a short half time of 3-5 hours and bioavailability of diltiazem for oral administration of about $40 \%$. Mucoadhesive buccal film diltiazem $\mathrm{Hcl}$ release the drug to the buccal mucosa so the first pass metabolism can be avoided because of its absorption through the venous system that flows from the cheek. The aim of this study was to study the effect of polyvinyl pyrrolidone (PVP) and chitosan polymers on swelling index, residence time and mucoadhesive strength of diltiazem $\mathrm{HCl}$ in mucoadhesive buccal film diltiazem $\mathrm{HCl}$. The prepared film was evaluated for swelling index, mucoadhesive strength and mucoadhesive residence time. The optimal amount for PVP is $1 \mathrm{mg}$ and chitosan is $25 \mathrm{mg}$. The combination of polymers with this amount can produces a swelling index, mucoadhesive strength, and mucoadhesive residence time are 3,641; 63,867 gF; and 352,667 minutes and the highest desirability value is 0.727 .
\end{abstract}

Keywords: mucoadhesive buccal film, diltiazem Hcl, PVP, chitosan

\begin{abstract}
Abstrak
Diltiazem $\mathrm{HCl}$ adalah golongan benzoatiazepin penghambat kanal kalsium (calcium channel blocker) yang digunakan dalam pengobatan angina pektoris, aritmia, dan hipertensi. Diltiazem $\mathrm{HCl}$ mengalami first pass metabolism di hati, waktu paruh yang pendek yakni 3-5 jam dan bioavailabilitas diltiazem pada pemberian oral sekitar $40 \%$. Sediaan mucoadhesive buccal film diltiazem $\mathrm{HCl}$ melepaskan obat ke mukosa buccal sehingga dapat menghindari first pass metabolism karena absorpsinya melalui sistem vena yang mengalir dari pipi. Tujuan penelitian ini adalah untuk mengetahui pengaruh polimer polivinil pirolidon (PVP) dan kitosan terhadap swelling index, waktu tinggal dan kekuatan mucoadhesive diltiazem $\mathrm{HCl}$ dalam sediaan mucoadhesive buccal film diltiazem $\mathrm{HCl}$. Sediaan film dilakukan evaluasi swelling index, kekuatan mucoadhesive dan waktu tinggal mucoadhesive. Jumlah optimum untuk PVP adalah $1 \mathrm{mg}$ dan kitosan sebesar $25 \mathrm{mg}$. Kombinasi polimer dengan jumlah tersebut dapat menghasilkan swelling index, kekuatan mucoadhesive, dan waktu tinggal mucoadhesive yaitu 3,$641 ; 63,867 \mathrm{gF}$; dan 352,667 menit dan nilai desirability tertinggi yaitu 0,727.
\end{abstract}

Kata kunci: mucoadhesive buccal film, diltiazem HCl, PVP, kitosan 


\section{Pendahuluan}

Hipertensi dapat didefinisikan sebagai tekanan darah persisten dimana tekanan sistoliknya diatas $140 \mathrm{mmHg}$ dan tekanan diastolik diatas $90 \mathrm{mmHg}$. Hipertensi merupakan penyebab utama terjadinya penyakit kardiovaskuler seperti gagal jantung, gagal ginjal, dan stroke yang saat ini menjadi penyebab kematian nomer satu di dunia. Berdasarkan Riskesdas tahun 2018, prevalensi hipertensi di Indonesia yang diukur pada penduduk dengan usia $\geq 18$ tahun adalah sebanyak 34,1\% [1]. Pedoman JNC 8 merekomendasikan sasaran terapi hipertensi adalah tekanan darah kurang dari 140/90 $\mathrm{mmHg}$. Diltiazem $\mathrm{HCl}$ adalah golongan benzoatiazepin penghambat kanal kalsium (calcium channel blocker) yang digunakan dalam pengobatan angina pektoris, aritmia, dan hipertensi. Diltiazem $\mathrm{HCl}$ hampir sepenuhnya diserap di saluran pencernaan setelah dosis oral, tetapi mengalami first pass metabolism di hati. Diltiazem $\mathrm{HCl}$ memiliki waktu paruh yang pendek yakni 3-5 jam dan bioavailabilitas diltiazem pada pemberian oral sekitar 40\% dengan konsentrasi plasma puncak terjadi sekitar 3 hingga 4 jam. Sekitar $80 \%$ diltiazem $\mathrm{HCl}$ terikat pada protein plasma [2]. Untuk mengatasinya digunakan rute alternatif yaitu penghantaran obat melalui buccal. Kelebihan rute buccal yaitu dapat untuk penghantaran secara sistemik karena jaringannya tervaskularisasi baik dan mukosanya relatif permeabel, sehingga dapat meningkatkan bioavailabilitas obat karena obat tidak terdegradasi dalam saluran cerna dan mengalami first pass metabolism.

Absorpsi yang optimal juga diperlukan agar jumlah zat aktif yang masuk ke sirkulasi sistemik berada pada dosis terapi. Hal ini dapat dicapai bila sediaan obat memiliki waktu kontak yang baik dengan mukosa buccal, yaitu dengan menformulasikan obat menjadi bentuk sediaan yang bersifat mucoadhesive. Film yang melepaskan obat ke mukosa buccal dapat menghindari first pass metabolism karena absorpsinya melalui sistem vena yang mengalir dari pipi [3].

Faktor-faktor yang mempengaruhi efektifitas sediaan film yaitu swelling index, kekuatan mucoadhesive, dan waktu tinggal mucoadhesive. Sediaan film memerlukan polimer yang bersifat mucoadhesive dan memiliki sifat mekanik yang baik (kuat dan lentur) untuk menghasilkan film buccal mucoadhesive yang baik. PVP dipilih karena dapat meningkatkan swelling index pada film karena kelarutannya yang baik. Kitosan memiliki sifat mucoadhesive yang baik dan pembentukan kekuatan ikatan yang baik dengan musin [4]. Kombinasi kitosan dan PVP menunjukkan karakteristik mucoadhesive dan pembengkakan yang baik [5].

Berdasarkan pemaparan diatas, maka perlu dilakukan penelitian untuk mendapatkan formula optimum dalam sediaan muchoadesive buccal film diltiazem hidroklorida pada kombinasi kitosan dan PVP. Setiap formula akan dibandingkan untuk melihat pengaruh PVP dan kitosan dengan variasi jumlah terhadap swelling index, kekuatan mucoadhesive, dan waktu tinggal mucoadhesive serta analisis menggunakan FTIR, dan pelepasan obat.

\section{Metode Penelitian Alat dan Bahan}

Peralatan yang digunakan dalam penelitian ini adalah alat-alat gelas, neraca analitik (Adventurer ${ }^{T M}$ Ohaus, USA), oven (Memmert Germany), pH meter, desikator, mortir, stamper, hot plate, mikrometer sekrup, alat uji disolusi tipe dayung, TA.XT plus Texture Analyzer, spektrofotometer FTIR Alpha Bruker, spektrofotometer (Genesys 10S, Thermo Scientific, USA), dan software Design Expert expert trial versi 10.0 .0

Bahan yang digunakan dalam penelitian ini adalah Diltiazem $\mathrm{HCl}$ (Supriya Lifescience Ltd.-India), PVP K-30 (BrataChem), kitosan (BrataChem), Propilen Glikol (BrataChem), Aquadestilata, $\mathrm{NaOH}, \mathrm{HCl}$, mukosa kambing jantan usia 3-4 tahun dari tempat penjagalan.

\section{Pembuatan dan Evaluasi Sediaan Buccal Film Diltiazem $\mathrm{HCl}$}

Bahan aktif dan polimer PVP dilarutkan dalam akuades, dan kitosan dilarutkan dalam asam asetat $1 \%$. Ketiga larutan tersebut diaduk sampai homogen, selanjutnya campuran tersebut ditambahkan plasticizer propilen glikol dan diaduk dengan kecepatan $100 \mathrm{rpm}$ selama 15 menit. Setelah homogen campuran dituang kedalam cetakan berdiameter $9 \mathrm{~cm}$ dan didiamkan selama semalam pada suhu kamar dengan ditutup alumunium foil untuk mendapatkan larutan yang jernih dan bebas gelembung. Esok harinya campuran dalam cetakan dikeringkan dalam oven pada suhu $50^{\circ} \mathrm{C}$ selama 20 jam. Film kering yang didapatkan dipotong dengan ukuran $2 \times 1 \mathrm{~cm}$. 
Susunan formula film untuk satu kali pembuatan dalam 1 cetakan (31 film) dapat dilihat pada Tabel 1.

Tabel 1. Susunan Formula

\begin{tabular}{|c|c|c|c|c|c|}
\hline Bahan & F1 & FA & FB & FAB & $\begin{array}{l}\text { Fungsi } \\
\text { Bahan }\end{array}$ \\
\hline $\begin{array}{l}\text { Diltiazem } \\
\mathrm{HCl}\end{array}$ & $0,93 \mathrm{~g}$ & $\begin{array}{c}0,93 \\
g\end{array}$ & $\begin{array}{c}0,93 \\
g\end{array}$ & $0,93 \mathrm{~g}$ & Bahan aktif \\
\hline PVP K-30 & $\begin{array}{c}0,031 \\
g\end{array}$ & $\begin{array}{c}0,15 \\
5 \mathrm{~g}\end{array}$ & $\begin{array}{c}0,03 \\
1 \mathrm{~g}\end{array}$ & $\begin{array}{c}0,155 \\
\mathrm{~g}\end{array}$ & $\begin{array}{l}\text { Polimer } \\
\text { former }\end{array}$ \\
\hline Kitosan & $0,62 \mathrm{~g}$ & $\begin{array}{c}0,62 \\
g\end{array}$ & $\begin{array}{c}0,9 \\
g\end{array}$ & $0,9 \mathrm{~g}$ & $\begin{array}{l}\text { Polimer } \\
\text { mucoadhe } \\
\text { sive }\end{array}$ \\
\hline $\begin{array}{l}\text { Propilen } \\
\text { glikol }\end{array}$ & $1,24 \mathrm{~g}$ & $\begin{array}{c}1,24 \\
g\end{array}$ & $\begin{array}{c}1,24 \\
g\end{array}$ & $1,24 \mathrm{~g}$ & Plasticizer \\
\hline Akuades & $10 \mathrm{~mL}$ & $\begin{array}{l}10 \\
\mathrm{~mL}\end{array}$ & $\begin{array}{l}10 \\
\mathrm{~mL}\end{array}$ & $10 \mathrm{Ml}$ & Pelarut \\
\hline $\begin{array}{l}\text { Asam } \\
\text { asetat } \\
1 \%\end{array}$ & $27 \mathrm{~mL}$ & $\begin{array}{l}27 \\
\mathrm{~mL}\end{array}$ & $\begin{array}{l}27 \\
\mathrm{~mL}\end{array}$ & $27 \mathrm{~mL}$ & Pelarut \\
\hline
\end{tabular}

\section{Evaluasi Buccal Film Diltiazem HCL}

Pengujian organoleptis

Pengujian oragnoleptis meliputi pengamatan secara visual seperti warna, bentuk, dan kondisi permukaan serta bau dan rasa buccal film yang dihasilkan.

\section{Pengujian Keseragaman Ketebalan Film}

Pengujian ini dilakukan dengan cara mengambil 3 film secara acak, masing-masing ketebalan diukur pada 5 titik yang berbeda menggunakan mikrometer sekrup.

\section{Pengujian Keseragaman Bobot Film}

Pengujian ini dilakukan dengan mengambil 3 sampel film, kemudian ditimbang pada timbangan digital satu per satu. Selanjutnya dihitung bobot rata-rata dan standar deviasinya

\section{Pengujian Ketahanan Lipat}

Daya tahan lipat dari film ditentukan dengan melipat satu film berulang kali di tempat yang sama sampai rusak atau dilipat hingga 200 kali secara manual [4].

\section{Pengujian pH Permukaan}

Pengujian ini dilakukan dengan cara merendam satu film dengan $10 \mathrm{~mL}$ aquadest dalam cawan petri selama 1 jam pada suhu kamar, kemudian $\mathrm{pH}$ diukur menggunakan $\mathrm{pH}$ meter [4].

\section{Penetuan Keseragaman Kandungan Diltiazem $\mathrm{HCl}$}

Penentuan keseragaman kadar diltiazem $\mathrm{HCl}$ dilakukan dengan menentukan panjang gelombang dengan konsentrasi 8 $\mu \mathrm{g} / \mathrm{mL}$ dalam dapar fosfat $\mathrm{pH} 6,6$. Kemuadian kurva baku baku diltiazem $\mathrm{HCl}$ dibuat dengan konsentrasi 4,6,8,10, dan 12 ppm. Keseragaman kadar ditentuka dengan film yang ukuran 2x1 cm diekstraksi menggunakan larutan dapar fosfat $\mathrm{pH}$ 6,6 dengan bantuan magnetic stirer selama 1 jam dan diencerkan hingga diperoleh larutan dengan kadar 6 ppm. Keseragaman kandungan diltiazem $\mathrm{HCl}$ dihitung dengan menggunakan persamaan.

\section{Uji Swelling Index}

Pengjian ini dilakukan dengan menimbang film yang dipilih ( $\left.W_{0}\right)$ kemudian film diletakkan di cawan petri yang berisi $5 \mathrm{~mL}$ larutan dapar fosfat $\mathrm{pH}$ 6,6 dan dibiarkan membengkak. Setiap interval waktu $0,5,1,0,2,0$ dan 4,0 jam, film diambil dengan hati-hati dan ditimbang kembali (Wt). Tingkat pembengkakan dihitung menggunakan rumus:

$$
S . I=\left(w t-w_{0}\right) / w_{0}
$$

\section{Uji Kekuatan Mucoadhesive}

Uji kekuatan mucoadhesive film dilakukan menggunakan alat Texture Analyzer yang dihubungkan dengan komputer dan dijalankan dengan XTRA Dimension Software. Jaringan buccal kambing ditempelkan di lempeng alat dengan posisi mukosa menghadap ke arah luar. Alat dinyalakan dan probe diatur untuk memberikan gaya sebesar $500 \mathrm{gF}$ dengan kecepatan $0,5 \mathrm{~mm} /$ detik $\mathrm{di}$ atas jaringan tersebut. Film dan mukosa dibiarkan kontak 30 detik, dan kemudian probe diangkat dengan kecepatan $1 \mathrm{~mm} /$ detik [6].

\section{Uji Waktu Tinggal Mucoadhesive}

Film dilekatkan pada jaringan buccal kambing dan kemudian diletakkan pada object glass di bagian tengah menggunakan perekat sianoakrilat dan ditempatkan di tepi beaker glass $500 \mathrm{~mL}$. Salah satu sisi film dibasahi dengan medium dapar fosfat $\mathrm{pH}$ 6,6 dan dilekatkan di jaringan buccal kambing dengan bantuan ujung jari selama 30 detik tanpa penekanan. Beaker glass diisi $250 \mathrm{~mL}$ medium dapar fosfat $\mathrm{pH}$ 6,6 dan disimpan pada suhu $37^{\circ}$ $\pm 0,5^{\circ} \mathrm{C}$ disertai pengadukan dengan magnetic stirer dengan kecepatan $50 \mathrm{rpm}$ dan diamati selama 6 jam [7].

\section{Analisis Data \\ Hasil pengujian swelling index, kekuatan mucoadhesive dan waktu tinggal}


diltiazem $\mathrm{HCl}$ diperoleh nilai untuk setiap respon, sehingga didapatkan persamaan umum desain faktorial $\mathrm{Y}=\mathrm{b} 0+\mathrm{baXA}+\mathrm{bbXB}+\mathrm{bab} \mathrm{XAXB}$ menggunakan software design expert versi 11.

\section{Verifikasi}

Respon hasil percobaan ditentukan lagi dari uji swelling index, waktu tinggal mucoadhesive, dan kekuatan mucoadhesive. Prediksi respon desain faktorial dengan dengan respon hasil percobaan tersebut dibandingkan secara statistik dengan uji-t (One Sample T-test) dengan derajat kepercayaan 95\%. Tingkat signifikansi $\mathrm{p}>0,05$ maka dinyatakan tidak signifikan [8].

\section{Hasil}

Hasil penelitian menunjukan bahwa keempat formula memiliki tekstur lentur, tidak berbau, berwarna agak kekuningan dan transparan, permukaan kering dan halus, dan rasanya sedikit manis. FAB memiliki ketebalan paling besar dan F1 memiliki ketebalan paling kecil, dengan nilai ketebalan $F A B>F B>F A>F 1$. Hasil pengujian keseragaman bobot film adalah $\mathrm{FAB}>\mathrm{FB}>\mathrm{FA}>\mathrm{F} 1$, serta nilai ketahanan lipat film pada keempat formula memiliki nilai yang lebih dari 200 kali lipatan.

Nilai $\mathrm{pH}$ sediaan yang didapatkan adalah berkisar 5,58-5,82. Persamaan regresi hasil pengukuran kurva baku diltiazem $\mathrm{HCl}$ didapatkan hasil yang linier yaitu $y=0,0577 x$ 0,0246 dengan nilai $r=0,99985$, sedangkan nilai $V_{x_{0}}=2,2963$ dan nilai $X p=1,4069$. Kurva baku diltiazem $\mathrm{HCl}$ dalam larutan dapar dapat dilihat pada Gambar 2.

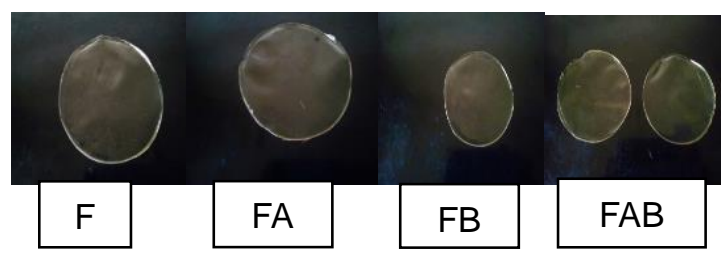

Gambar 1. Sediaan Mucoadhesive Buccal Film Diltiazem $\mathrm{HCl}$

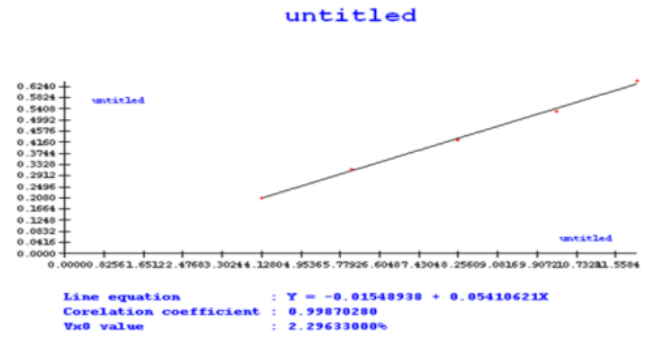

Gambar 2.Kurva Baku Diltiazem $\mathrm{HCl}$ dalam Larutan Dapar Fosfat pH 6,6

Kandungan kadar diltiazem $\mathrm{HCl}$ pada sediaan film diperoleh berkisar antara 93,485\%98,690\%; sehingga pada keempat formula telah memenuhi rentang yang dipersyaratkan yaitu $85-115 \%$. Hasil pengujian swelling index, kekuatan mucoadhesive, dan waktu tinggal mucoadhesive dapat dilihat pada Tabel 2.

Tabel 2. Hasil pengujian swelling index, kekuatan mucoadhesive, dan waktu tinggal mucoadhesive

\begin{tabular}{lccc}
\hline & Swelling Index & $\begin{array}{c}\text { Kekuatan } \\
\text { Mucoadhesive } \\
(g F)\end{array}$ & $\begin{array}{c}\text { Waktu Tinggal } \\
\text { (menit) }\end{array}$ \\
\hline $\mathrm{F} 1$ & $3,248 \pm 0,103$ & $25,3 \pm 1.305$ & $273,667 \pm 3,512$ \\
\hline $\mathrm{F} 2$ & $4,603 \pm 0,052$ & $33,9 \pm 0,721$ & $295,667 \pm 2,517$ \\
\hline $\mathrm{F} 3$ & $3,641 \pm 0,097$ & $63,87 \pm 0,751$ & $352,667 \pm 2,517$ \\
\hline $\mathrm{F} 4$ & $4,055 \pm 0,0469$ & $57,13 \pm 2,250$ & $321,667 \pm 2,517$ \\
\hline Keterangan : Data disajikan dalam rerata \pm SD (n=3). \\
Hasil analisis data, formula optimum \\
yang didapatkan mempunyai nilai prediksi \\
swelling index, kekuatan mucoadhesive, dan \\
waktu tinggal mucoadhesive yaitu 3,641; 63,867 \\
gF; dan 352,667 menit dan nilai desirability \\
tertinggi yaitu 0,727 dengan jumlah kitosan \\
sebesar 25 mg dan PVP sebesar 1 mg. hasil \\
verifikasi formula optimum didapatkan nilai \\
tingkat signifikansi >0,05 yang berarti data tidak \\
berbeda secara bermakna.
\end{tabular}

\section{Pembahasan}

Hasil uji Swelling Index formula dengan jumlah PVP lebih besar (FA dan FAB) memberikan nilai swelling index yang lebih besar. Efek faktor PVP dapat meningkatkan respon swelling index, sedangkan kelarutan kitosan yang buruk membatasi pembengkakan film. PVP dapat meningkatkan keterbasahan permukaan dan mengakibatkan penetrasi air didalam matriks, sehingga terjadi pembengkakan pada film. Pembengkakan polimer meningkatkan ikatan mekanik dengan pembukaan mucoadhesive site untuk ikatan 
hidrogen atau interaksi elektrostatik antara polimer dan jaringan musin [9].

Hasil uji kekuatan mucoadhesive menunjukkan bahwa semakin banyak jumlah PVP maka kekuatan mucoadhesive akan semakin kecil karena kemungkinan dapat melonggarkan kekuatan ikatan dengan mukosa sehingga membuat ikatan semakin lemah. Kitosan memiliki sifat mucoadhesive yang baik dan menghasilkan kekuatan ikatan yang baik dengan musin. Begitu juga dengan hasil waktu tinggal mucoadhesive, peningkatan jumlah PVP memungkinkan terjadinya pembengkakan film dan membuat ikatan hidrogen lebih lemah [4].

Analisis data yang menghasilkan formula optimum dengan jumlah kitosan sebesar $25 \mathrm{mg}$ dan PVP sebesar $1 \mathrm{mg}$. Formula optimum yang didapatkan mempunyai nilai prediksi swelling index, kekuatan mucoadhesive, dan waktu tinggal mucoadhesive yaitu 3,$641 ; 63,867 \mathrm{gF}$; dan 352,667 menit dan nilai desirability tertinggi yaitu 0,727 . Hasil percobaan pada ketiga respon formula optimum dilakukan verifikasi, kemudian dibandingkan dengan prediksi respon dari desain faktorial secara statistik menggunakan uji-t (One Sample T-test) dengan taraf kepercayaan $95 \%$. Nilai tingkat signifikansi yang didapat $>0,05$ yang berarti data tidak berbeda secara bermakna, sehingga dapat disimpulkan persamaan yang dihasilkan dari desain dapat memprediksi dengan baik.

\section{Simpulan dan Saran}

Hasil penelitian ini menunjukkan bahwa faktor PVP dapat meningkatkan nilai respon swelling index dan kekuatan mucoadhesive, serta menurunkan nilai respon waktu tinggal mucoadhesive pada sediaan film. Faktor kitosan dapat meningkatkan nilai kekuatan dan waktu tinggal mucoadhesive, serta menurunkan nilai respon swelling index pada sediaan film. Komposisi optimum PVP dan kitosan pada sediaan mucoadhesive buccal film diltiazem $\mathrm{HCl}$ masing-masing adalah sebesar $1 \mathrm{mg}$ dan $25 \mathrm{mg}$

Beberapa saran dari penelitian ini yaitu in vivo untuk mengetahui efektifitas pada sediaan film, pengujian stabilitas untuk mengetahui stabilitas fisika kimia sediaan mucoadhesive buccal film diltiazem $\mathrm{HCl}$ dan pengujian moisture content untuk mengetahui kamdungan air atau kelembapan sediaan film.

\section{Daftar Pustaka}

[1] Kemenkes RI. 2018. Hasil Utama Riskesdas 2018. Jakarta: Kemenkes RI.

[2] Sweetman, S. C. Martindale: The Complete Drug Reference. $36^{\text {th }}$ ed. London: Pharmaceutical Press. 2009.

[3] Morales JO, McConville JT. Manufacture and characterization of mucoadhesive buccal films. European Journal of Pharmaceutics and Biopharmaceutics. 2011; 77(2):187-199.

[4] Deshmane SV, Channawar MA, Chandewar AV, Unmesh M, BiyaniKR. Chitosan based sustained release mucoadhesive buccal patches containing verapamil hcl. International Journal of Pharmacy and Pharmaceutical Sciences. 2009; 1:216-229.

[5] Patel RS, Poddar SS. Development and characterization of mucoadhesive buccal patches of salbutamol sulphate. Current Drug Delivery. 2009; 6(1):140-144.

[6] Somepalli N, Moru CS, Gottipati DB. Krishna V. Formulation and evaluation of buccal films of salbutamol sulphate. Mintage Journal of Pharmaceutical \& Medical Sciences. 2013; 2(3):1-4.

[7] Patel V M, Prajapati BG, Patel MM. Design and characterization of chitosan-containing mucoadhesive buccal patches of propranolol hydrochloride. Acta Pharm. 2007; 57:61-72.

[8] Sugiyono. Metode Penelitian Pendidikan: Pendekatan Kuantitatif, Kualitatif, Dan R\&D. Bandung: Alfabeta. 2016.

[9] Koland M, Vijayanarayana K, Charyulu R, Prabhu $P$. In vitro and in vivo evaluation of chitosan buccal films of ondansetron hydrochloride. International Journal of Pharmaceutical Investigation. 2011; 1(3):164. 